\title{
REPRESENTAÇÕES SOCIAIS SOBRE USO DE CANNABIS ENTRE JOVENS: ESTUDO COMPARATIVO
}

Paola Souza Dias

APAE - São João del-Rei, MG

Recebido em: 24/03/2020

Fernanda Gomes Palata

$1^{\text {a }}$ revisão em: $11 / 10 / 2020$

Aceito em: 03/11/2020

Centro de Saúde do Sambizanga, Luanda, Angola

Marcelo Dalla Vecchia

Universidade Federal de São João del-Rei, MG

\section{RESUMO}

Buscou-se identificar e comparar as representações sociais sobre o consumo da maconha na perspectiva de dois grupos de jovens: frequentadores de uma universidade pública, e participantes não-universitários de um projeto social com oriundos de bairros periféricos. Os dados foram coletados em grupos focais, cada um com seis participantes, sendo a análise fundamentada na teoria das representações sociais e operacionalizada pela análise temática. Foram delimitadas categorias a posteriori. imagens da maconha, visão dos familiares, papel/lugar da maconha, motivação/influência para o uso, contexto de uso, posicionamento da escola/universidade e consequências. Observaram-se aproximações entre os grupos sobre a percepção de inocuidade da maconha por ser produto natural e a dificuldade de dialogar a respeito com os familiares, mas também diferenças, por exemplo, quanto a ser ou não a maconha porta de entrada para outras drogas. Discutir sobre a maconha ainda gera resistências e traz tabus, acentuando a necessidade de promoção de diálogos.

Palavras-chave: cannabis sativa; maconha; teoria das representações sociais; juventude; grupos focais. 


\section{SOCIAL REPRESENTATIONS OF CANNABIS USE AMONG YOUNGSTERS: COMPARATIVE STUDY}

\section{ABSTRACT}

We sought to identify and compare the social representations of marijuana use from the perspective of two groups of young people: those attending a public university, and non-university participants attending a social project with people from suburbs. Data were collected in focus groups, each with six participants, and the analysis was based upon the theory of social representations and carried out through thematic analysis. A posteriori categories were delimited: images of marijuana, family members' view, marijuana's role/place, motivation/influence for use, context of use, school/university positioning and consequences. There were similarities between the groups regarding the perception of the safety of marijuana as a natural product and the difficulty of talking about it within the family, but also differences, for example, as to whether or not marijuana is the gateway to other drugs. Discussing marijuana still generates resistance and brings taboos, accentuating the need to promote dialogues.

Keywords: cannabis sativa; marijuana; social representations theory; youngsters; focus groups.

\section{REPRESENTACIONES SOCIALES DE LA CANNABIS ENTRE LOS JÓVENES: ESTUDIO COMPARATIVO}

\section{RESUMEN}

Se buscó identificar y comparar representaciones sociales del consumo de marihuana desde dos grupos de jóvenes: los que asisten a una universidad pública y los participantes no universitarios en un proyecto social con personas de los barrios periféricos. Los datos se recolectaron en grupos focales, cada uno con seis participantes, y el análisis se basó en la teoría de las representaciones sociales mediante análisis temático. Se delimitaron categorías a posteriori. imágenes de la marihuana, visión de los familiares, rol/lugar de la marihuana, motivación/influencia para el uso, contexto de uso, posicionamiento de la escuela/universidad y consecuencias. Hubo similitudes en cuanto a la percepción de la seguridad de la marihuana y la dificultad de hablar con los familiares, pero también diferencias, por ejemplo, si la marihuana es o no la puerta de entrada. Hablar de la marihuana aún genera resistencias y trae tabúes, lo que acentúa la necesidad del diálogo.

Palabras clave: cannabis sativa; marijuana; teoría de las representaciones sociales; jóvenes; grupos focales. 


\section{INTRODUÇÃO}

O consumo da maconha é um fenômeno psicossocial que tem sido foco de debates acalorados tanto entre especialistas quanto entre o público leigo (Sousa, Santos, \& Aléssio, 2018). Conhecida popularmente como maconha, a Cannabis Sativa é a denominação científica para uma espécie de planta abundante em regiões tropicais e temperadas. Carlini (2006a) aponta haver indícios de que a maconha seja originária da Ásia Central. Para Malcher-Lopes e Ribeiro (2007), a planta pode ter se espalhado pelo mundo devido aos movimentos migratórios de nômades e à atividade de comerciantes. Observa-se que vem sendo utilizada por distintos grupos socioculturais e com diferentes fins: medicinal, religioso, industrial, recreativo e lúdico. Foram identificados mais de 60 canabinoides com princípios psicoativos, para além dos mais comumente conhecidos, o tetraidrocanabinol e o canabidiol (Malcher-Lopes \& Ribeiro, 2007; Saito, Wotjak, \& Moreira, 2010).

De acordo com Paulo e Abreu (2015) e com MacRae e Simões (2000), a cannabis teria sido trazida ao Brasil nos navios negreiros por povos africanos escravizados, recebendo denominações como 'fumo de Angola', 'pito do pango', 'liamba', 'diamba' e 'cânhamo'. Posteriormente, passou a ser cultivada e utilizada por grupos indígenas e populações das periferias urbanas (Malcher-Lopes \& Ribeiro, 2007; Saad, 2018).

Carlini (2006a) aponta que a repressão ao uso da maconha se intensificou no Brasil na década de 1930, quando passou a ser criminalizada por um decreto que determinava o controle do uso de substâncias narcóticas, posicionando a cannabis na mesma categoria do ópio e da cocaína. As políticas proibicionistas ganharam espaço crescente no país com base em componentes culturais, políticos e econômicos. Segundo o Centro de Referência Técnica em Psicologia e Políticas Públicas - CREPOP (2019), a proibição da cannabis, por exemplo, fez parte da criminalização da cultura dos povos negros que foram escravizados, o que se reflete ainda atualmente, através da seletividade penal por meio de um traço étnico-racial.

A partir da década de 1960, o uso da maconha ganhou espaço entre a classe média urbana. Nos anos seguintes, mais propriamente durante o período militar, o uso da maconha constituiu-se como um "estilo alternativo de vida, uma expressão de liberdade de pensamento e sensações, praticada por grupos de jovens" (MacRae \& Simões, 2000, p. 22).

O preconceito e a estigmatização são fenômenos enfrentados pelos usuários da maconha e essa prática pode culminar com a segregação. Há uma discussão em torno da descriminalização do porte da maconha, em um intenso e acalorado debate público, com posicionamentos diferenciados por vários segmentos da sociedade (Coutinho, Araújo, \& Gontiès, 2004; Moreira, Carvalho, Ribeiro, \& Fernandes, 2016; Nascimento, 2018). 
No Brasil, a Lei n. 6.368 de 1976 foi revogada em face da Lei n. 11.343 de 2006 (conhecida como Lei de Drogas), e posteriormente atualizada pela Lei n. 13.840, de 2019. Essa Lei estabelece que a prevenção do uso indevido de drogas deve ter por base atividades voltadas para a redução de riscos e vulnerabilidades e para a promoção e fortalecimento dos fatores de proteção, tendo como eixos a autonomia e a responsabilidade individual diante do uso de drogas (CREPOP, 2019). Apesar da mudança da Lei, argumenta-se a falta de transparência na distinção entre porte/uso e tráfico, com especialistas apontando que a legislação atual sobre drogas implicou no aumento significativo do número de indivíduos presos por tráfico, em especial mulheres. Borges (2018), nesse sentido, aponta que o Brasil possui a quinta maior população feminina de encarceradas no mundo, com idades compreendidas entre 18 e 29 anos, sendo em sua maioria negras. Rybka, Nascimento e Guzzo (2018) sustentam que um dos efeitos da chamada 'guerra às drogas' são a aniquilação e o encarceramento em massa de jovens, pobres e negros, o que é corroborado por Borges (2018), que argumentam que a cultura de criminalização da pobreza e da população negra é um fator determinante para o aumento do encarceramento no Brasil.

Em 2005 foi realizado o II Levantamento Domiciliar sobre Uso de Drogas Psicotrópicas, desenvolvido pela Secretaria Nacional de Políticas sobre Drogas (SENAD) em parceria com o Centro Brasileiro de Informações sobre Drogas Psicotrópicas (CEBRID), que constatou, dentre os quase oito mil entrevistados com idades variando entre 12 e 65 anos, de 108 municípios distintos e com mais de 200 mil habitantes, que $8,8 \%$ já fizeram uso de maconha alguma vez na vida, $2,6 \%$ faziam uso da maconha no ano da pesquisa, $1,6 \%$ faziam uso no mês da pesquisa e a média de idade para iniciar o consumo da maconha foi de 17,7 anos de idade (Carlini, 2006b). Em 2012 a Unidade de Pesquisa em Álcool e Drogas (UNIAD) e o Instituto Nacional de Políticas Públicas do Álcool e Outras Drogas (INPAD) da Universidade Federal de São Paulo (UNIFESP), por meio do II Levantamento Nacional de Álcool e Drogas, evidenciou que 5,8\% de adultos e $4,3 \%$ de adolescentes já fizeram uso da maconha alguma vez na vida, e que $25 \%$ de adultos e 3,4\% de adolescentes fizeram uso da maconha no último ano (INPAD, 2014). Em 2017, a Fundação Oswaldo Cruz e o Instituto de Comunicação e Informação Científica e Tecnológica em Saúde, em parceria com a SENAD, publicaram o III Levantamento Nacional sobre o Uso de Drogas pela População Brasileira. No ano de 2015, 16.273 pessoas com idades entre 12 e 65 anos, em todo o país foram entrevistadas. Os dados demonstram que $7,7 \%$ da população entrevistada consumiu maconha ao menos uma vez na vida, 2,5\% fizeram uso no ano da pesquisa e 1,5\% nos últimos 30 dias (Bastos, Vasconcellos, Boni, Reis, \& Coutinho, 2017). Percebe-se que as três pesquisas convergem no que diz respeito ao fato da maconha ser a substância ilícita com maior prevalência de uso na população brasileira, realidade observada mundialmente (United Nations Office on Drugs and Crime [UNODC], 2017).

No que tange à juventude, Dayrell, Moreira e Stengel (2011) afirmam que a possibilidade de diálogo entre diversos pesquisadores que trabalham com essa 
temática se destaca na consideração dos processos de subjetivação, do reconhecimento dos jovens como sujeitos ativos transformados pelo e transformadores do contexto social em que se encontram inseridos. Não obstante, nas suas relações com os pares e a sociedade, manifestam seus conflitos, impasses e contradições ao se reafirmarem como sujeitos portadores de direitos. Tavares, Silva, Tomaz, Bandeira e Nepomucena (2008) e Cordeiro, Silva e Dalla Vecchia (2016) afirmam que a relação entre juventude e drogas se faz presente cotidianamente em diversos espaços da sociedade que vão desde a família e a escola, até o sistema prisional (delegacias e presídios) e instituições para cumprimento de medidas socioeducativas para crianças e adolescentes.

Ao passo que o uso da maconha por parte dos jovens tem crescido significativamente, o contexto familiar se torna propício para estudar o fenômeno de modo mais aprofundado. Segundo MacRae e Simões (2000), o uso da maconha constitui-se como uma preocupação frequente dos pais em relação ao futuro dos filhos. Essa atitude é compreensível, na medida em que o consumo desse psicoativo, assim como de qualquer outra droga, pode acarretar prejuízos. Os efeitos da maconha podem ser variáveis, dependendo da quantidade consumida, frequência do uso, combinação com outras drogas lícitas ou ilícitas e outros fatores relativos ao ambiente, estado emocional e às expectativas do usuário (Bohn et al., 2018; Saad, 2018; MacRae \& Simões, 2000).

O consumo de drogas, em um sentido amplo (lícitas, ilícitas e prescritas), encontra-se presente e influencia várias esferas da sociedade; sendo assim, o uso por universitários faz parte desse contexto (Souza, Araújo, Silva, Moura, \& Machado, 2011). O ingresso na universidade proporciona novas experiências e, via de regra, maior autonomia por parte dos jovens, podendo, assim, se tornar um período crítico de maior vulnerabilidade para iniciar e/ou sustentar o uso de álcool e outras drogas (Andrade, Duarte, \& Oliveira, 2010; Peuker, Fogaça, \& Bizarro, 2006).

A SENAD, em conjunto com o Grupo Interdisciplinar de Estudos de Álcool e Drogas (GREA), da Faculdade de Medicina da Universidade de São Paulo, realizou o I Levantamento Nacional sobre o Uso de Álcool, Tabaco e Outras Drogas entre Universitários das 27 Capitais Brasileiras. A pesquisa foi realizada em 100 instituições de ensino superior, públicas e privadas. Como resultado dessa pesquisa, destaca-se que as drogas relatadas com maior frequência de uso na vida são: álcool $(86,2 \%)$, tabaco $(46,7 \%)$ e a maconha $(26,1 \%)$. Com relação à frequência do uso nos últimos 30 dias, foram referidos álcool (60,5\%), tabaco $(21,6 \%)$ e a maconha $(9,1 \%)$. Percebe-se que a maconha é a droga ilícita utilizada com maior frequência pelos jovens universitários (Andrade et al., 2010). De acordo com Carlini (2006b), foi possível observar que o uso de drogas é mais prevalente entre jovens universitários do que pela população geral brasileira das 108 maiores cidades do país. No que se refere ao uso de drogas pelos universitários, podem estar presentes diversos fatores pessoais como necessidade de autoafirmação do sujeito, afeto, busca de prazer, valores etc. (Fonseca, 
Azevedo, Araújo, Oliveira, \& Coutinho, 2007). Além disso, segundo Andrade et al. (2010), pode haver influência do ano acadêmico, do período de estudo e do gênero.

Para Sousa, Santos e Acioli Neto (2019) os fenômenos relacionados ao consumo de álcool e outras drogas são campo de investigação fértil para as ciências humanas, pois "são vividos cotidianamente, são simbolicamente construídos, integram dimensões da experiência individual, grupal e cultural, e constituem objeto de tensões políticas a respeito de como lidar com o outro e com as categorias de desvio e alteridade" (p.351).

Fonseca et al. (2007) apontam a importância das representações sociais na análise e compreensão de aspectos psicossocioculturais das práticas sociais que atravessam os processos de saúde-doença, como também dos atos de comunicação social e fenômenos grupais que influenciam a formação de condutas e normas que regem o pensamento social. Segundo Moscovici (2012), as representações sociais são um conjunto de ideias, valores e práticas que revelam as formas de conceber a realidade pelo ser humano em sua historicidade. São dotadas, ainda, de características próprias, comunicando-se entre si, emergindo em novas representações na medida em que se esvaem e originando-se de contextos interpessoais.

O estudo das Representações Sociais, segundo Jodelet (2001) faz parte de um modo de conhecimento distinto do conhecimento científico; no entanto, sua fidedignidade se radica na relevância em trazer à tona questões contemporâneas da vida social, evidenciando processos cognitivos e interações sociais constitutivos dessas questões. De acordo com Crusoé (2004), as representações sociais são, portanto, "uma proposta científica de leitura do conhecimento de senso comum" (p.107).

Conforme Moscovici (2012), para assimilar o desconhecido e construir as representações sociais são necessárias intervenções de dois processos básicos, intrinsecamente ligados e mediados por fatores sociais: ancoragem e objetivação. $O$ processo de ancoragem refere-se a classificar e nomear o desconhecido, sendo essa uma forma de inserir o objeto em uma rede simbólica existente a priori. A objetivação refere-se à concretização daquilo que foi subjetivamente elaborado e, depois, compartilhado, ganhando, assim, uma materialidade entendida como natural.

Além disso, visto que a teoria das representações sociais trata das formas de expressão do senso comum, Moscovici (2012) aponta para uma distinção entre o universo reificado e o universo consensual. No universo reificado ou científico, configura-se a ideia de que a compreensão da realidade é construída pela ciência, com objetividade e rigor lógico e metodológico. Por outro lado, o universo consensual é aquele que se constrói em conversações informais, expressando-se em atividades das vidas cotidianas dos sujeitos. Justamente por 
ser expressão do senso comum, o universo consensual é a base fundamental para a constituição das representações sociais.

Muitos estudos têm sido realizados ao longo dos anos para investigar as propriedades medicinais da maconha com relação a vários problemas de saúde e, mais recentemente, para o tratamento da dor (Lessa, Cavalcanti, \& Figueiredo, 2016). Não obstante, há estudos que apontam resultados negativos do consumo da maconha, que de acordo com o padrão de uso poderia causar prejuízos cognitivos, intoxicação, danos respiratórios para usuários crônicos, risco de acidentes, probabilidade de desenvolver dependência para usuários frequentes, possibilidade de comprometer as relações sociais e a organização financeira do usuário (Ribeiro et al., 2005).

Investigar os impactos sociais do consumo da maconha é econômica e socialmente relevante, tendo em vista que a maconha é a substância ilícita mais consumida no mundo. Dada a atualidade e premência do debate contemporâneo acerca da maconha, a teoria das representações sociais é acionada para contribuir como perspectiva teórica nesse estudo. Buscou-se, assim, compreender a realidade compartilhada sobre o consumo da maconha por um grupo de jovens universitários de um município de médio porte comparativamente a jovens não frequentadores da universidade e que fazem parte de um projeto social nesse mesmo município.

\section{MÉTODO}

O estudo desenvolvido consistiu em uma pesquisa qualitativa, que, como tal, procura enfatizar a compreensão de sentidos e significados constituídos por atores sociais específicos, recorrendo a hipóteses, métodos e técnicas científicas. Minayo (2007), nesse sentido, sustenta que o ciclo da pesquisa qualitativa deve ser desenvolvido em três etapas: a fase exploratória, o trabalho de campo e a análise e tratamento do material empírico e documental.

\section{PARTICIPANTES}

O público-alvo da pesquisa foram jovens estudantes. Um grupo foi composto por jovens regularmente matriculados em algum curso da universidade escolhida, localizada no interior do estado de Minas Gerais (Grupo 1), e o outro grupo por jovens não frequentadores da universidade, e que fazem parte de um projeto social que atende em sua maioria crianças e jovens de bairros periféricos da mesma cidade (Grupo 2).

A universidade em questão está localizada no interior do estado de Minas Gerais. Trata-se de uma universidade de médio porte, que oferece cursos de graduação em todas as áreas do conhecimento e também de pós-graduação. O município se caracteriza por ser uma cidade histórica, também de médio porte, com destaque na sua atividade econômica para o turismo, a indústria de laticínio e a 
agricultura familiar, sendo uma cidade-pólo administrativa da região em que se encontra.

O projeto social em questão trata-se de uma banda de música vinculada à igreja católica. A banda é convidada para participar de atividades religiosas, cívicas, sociais e culturais na cidade e região. Foi criada com o objetivo de incluir o adolescente e o jovem nas artes e na cultura, bem como promover a socialização, educação e profissionalização. O projeto recebe crianças a partir de oito anos de idade e a participação é livre; entretanto, observa-se que o público é composto em sua maioria por jovens de classes populares que residem em bairros periféricos da cidade. O projeto não conta com apoio financeiro do setor público.

Adotou-se como critério de inclusão no Grupo 1 a voluntariedade dos jovens, apresentar idade igual ou superior a 18 anos, estar devidamente matriculado e realizando um curso de graduação, e como critério de exclusão estar realizando os primeiros períodos dos respectivos cursos. Com relação ao Grupo 2 foram adotados os critérios de inclusão de voluntariedade de participação pelos jovens, apresentar idade igual ou superior a 18 anos e ser frequente no projeto social, e como critérios de exclusão não residir em um bairro periférico da cidade e estar matriculado em um curso superior. O Grupo 1, assim, ficou composto por universitários dos cursos de Engenharia Elétrica, História, Filosofia, Psicologia, Pedagogia e Geografia, sendo três homens e três mulheres, com idades entre 20 e 23 anos. Dois desses participantes são católicos e quatro não frequentam nenhuma religião. Todos os participantes têm renda de meio a um salário e contam com ajuda financeira dos familiares. O Grupo 2, por sua vez, consistiu em seis jovens advindos de quatro bairros da periferia da cidade que participavam do projeto social, sendo três homens e três mulheres, com idades compreendidas entre 18 e 25 anos. Destes, cinco são católicos e um não segue nenhuma religião. Com relação à renda, os participantes são em sua maioria dependentes dos familiares, que têm renda de até três salários-mínimos. Quatro dos participantes desse grupo estavam cursando o ensino médio na modalidade de Educação para Jovens e Adultos (EJA) e dois já haviam concluído o ensino médio em escolas públicas da cidade e estavam empregados.

\section{INSTRUMENTOS}

O trabalho de campo consistiu na realização de dois grupos focais, um com cada grupo de jovens citados anteriormente (Grupos 1 e 2). O grupo focal é uma técnica de entrevista grupal que se originou na Sociologia (Oliveira \& Freitas, 1998). Por meio do grupo focal se promovem discussões acerca de tópicos relacionados a um determinado assunto, possibilitando observar e registrar percepções, crenças, valores e atitudes dos participantes acerca do tema. Buscase criar um ambiente conveniente, tolerante e que garanta o anonimato dos participantes e o sigilo de suas falas, como um recurso para identificar o processo de produção de representações sociais (Westphal, Bógus, \& Faria, 1996). 
Os grupos focais dedicam-se à interação grupal com o intuito de ocasionar insights e informações relevantes que por meio de entrevistas individuais não seriam possíveis (Kind, 2004). A técnica demanda reuniões com duração média de uma hora e meia e com seis a doze integrantes (Minayo, 2007). Utilizou-se um roteiro de entrevista semiestruturada elaborado pelos autores, com perguntas que, de modo geral, buscavam identificar suas percepções acerca do uso da maconha, fatores que, a seu ver, influenciam o uso e as implicações que observam no decorrer desse uso.

Utilizou-se, ainda, um questionário sociodemográfico de autopreenchimento, formulado também pelos autores, para sistematizar características a fim de traçar um perfil dos participantes, contendo idade, gênero, escolaridade, curso, religião, renda, estado, cidade e bairro.

\section{PROCEDIMENTOS}

O grupo focal com os participantes do Grupo 1 foi realizada em uma sala de aula da universidade em questão e com o Grupo 2 nas dependências do projeto social do qual participavam. Em ambas as salas houve a preocupação dos pesquisadores com a garantia do sigilo e da confidencialidade para que os participantes pudessem oferecer seus depoimentos.

Os jovens que integraram o Grupo 1 foram convidados a participar da pesquisa por meio de uma comunidade virtual em uma rede social da qual eram membros. Já os jovens que participaram do Grupo 2 foram recrutados através de convite feito presencialmente pelos pesquisadores, com a intermediação do coordenador do projeto social.

Para a análise dos dados optou-se pela análise temática e delimitação de categorias, delimitadas a posteriori, recorrendo-se a conceitos da Teoria das Representações Sociais para viabilizar a compreensão e a comparação das representações sociais identificadas por intermédio da análise dos grupos focais. Em um primeiro momento foi realizada uma pré-categorização com base em trechos significativos que, posteriormente, foram articulados em categorias. Em seguida, foram comparadas as semelhanças e as diferenças entre tais categorias considerando-se os dois grupos de participantes.

\section{CONSIDERAÇÕES ÉTICAS}

O projeto em questão foi submetido para avaliação do Comitê de Ética em Pesquisa Envolvendo Seres Humanos da Universidade Federal de São João delRei (CEPSJ), tendo sido aprovado em 6 de dezembro de 2019 (Parecer no 3.750.086). Previamente à aplicação do questionário sociodemográfico e ao início do grupo focal solicitou-se aos participantes que lessem e assinassem o Termo de Consentimento Livre e Esclarecido (TCLE), explicitando o tipo de colaboração que se solicitava, que sua participação era voluntária e passível de desistência a qualquer momento, e que não haveria recompensa em participar. Garantiu-se 
também a confidencialidade dos relatos, bem como da identidade dos respectivos sujeitos, que consentiram com a gravação dos encontros.

\section{RESULTADOS E DISCUSSÃO}

A análise dos dados coletados possibilitou observar a constituição de representações em parte consensuais e em parte específicas pelos jovens participantes da pesquisa, sendo delimitadas assim as seguintes categorias: (a) imagens da maconha, (b) visão dos familiares acerca da maconha, (c) papel/lugar da maconha, (d) motivação/influência para o uso da maconha, (e) contexto de uso da maconha, (f) posicionamento da escola/universidade frente à maconha e (g) consequências decorrentes do uso.

\section{IMAGENS SOBRE A MACONHA}

Os dois grupos de jovens relatam observar falta de informação e desconhecimento sobre a maconha, sugerindo a necessidade de promover mais discussões sobre o tema. Uma pesquisa de opinião nacional realizada em 2014, com 3.007 entrevistas telefônicas, sobre as percepções dos brasileiros a respeito da descriminalização e legalização da maconha demonstrou que o debate sobre o tema é precário no Brasil, sendo TV e internet as principais fontes de informação e os entrevistados considerando-se mal informados a respeito do tema (Moreira et al., 2016).

Entre as semelhanças nos discursos a respeito das imagens da substância, foi observado que os atores sociais ancoram suas representações da maconha como uma planta inofensiva e, desse modo, ela é encarada como menos prejudicial, como uma droga que causa menos danos que as demais. Assim, seria o desconhecimento sobre a planta como um todo e os efeitos do seu consumo que geraria preconceito: "ela [maconha] pode viciar sim! Mas não igual ao crack e não na intensidade das outras". Ambos os grupos reconhecem que a maconha é uma droga ilícita e que seu uso ou porte pode vir a gerar problemas com a lei.

Quando os jovens do Grupo 2 falam sobre o usuário de maconha, ratificam as imagens correspondentes às pessoas sob efeito, isto é, como 'drogado', ao passo que as imagens sobre a substância relacionam-se ao tráfico, violência, morte e a outras drogas entendidas como mais 'perigosas' o que também foi verificado na pesquisa de Paulo e Abreu (2015). De acordo com Nascimento (2018), as representações sobre a identidade conferida aos usuários de drogas estigmatizadas são expressas geralmente de forma negativa como "o viciado que fará de tudo para manter este vício, inclusive roubar e matar" (p. 24). Contudo, salienta que a droga

não será o elemento determinante do modo pelo qual os sujeitos agem e irão agir no mundo e perante ao seu uso; 
ou seja, o sujeito não será meramente aqueles efeitos que a substância proporciona, mas sim, cada sujeito irá significá-los, de acordo com sua história de vida (Nascimento, 2018, p. 32).

Os participantes do Grupo 2 relataram, ainda, entender que, para eles, a maconha é 'porta de entrada' para o uso de outras drogas. No que concerne ao local do uso, entendem ser aceitável consumi-la em um local privado, mas inaceitável em espaços públicos: "mas a maioria das pessoas que se envolve com outras coisas, tipo coisas piores, a maioria delas começa pela maconha. Experimenta maconha assim... Mais fraca e tal... $E$ depois quer... Experimentar algo mais forte".

Na visão do Grupo 1, a imagem do usuário no senso comum corrobora os estereótipos de 'drogado', como exemplificado no relato da entrevista "meu primo, só da galera da minha cidade olhar para ele... Já viu que ele tem dread no cabelo todo, já olha torto assim... Aí todo mundo já fica assustado, mas ninguém fala abertamente sobre o assunto". Para esses jovens, haveria estereótipos com relação ao uso de maconha que seriam associados ao curso ao qual o jovem ingressou: "eu ia entrar para fazer o curso de Filosofia... Mas o pessoal me falava: 'o pessoal da Filosofia fuma maconha!' Tem esse estereótipo, né..."

O grupo relata falta de informações adequadas e desconhecimento, e que a maconha ainda é vista como um tabu, o que, para eles, desemboca em preconceitos. Na pesquisa de Nascimento (2018), muitos sujeitos que eram usuários sentiam-se inferiorizados, discriminados pela avaliação dos outros e isso afetou negativamente suas identidades. Isso pode ser evidenciado no seguinte relato:

Sempre sofri uma repressão muito grande lá em casa, por causa da questão da maconha e sofro ainda até hoje ... isso não é muito bem esclarecido com os meus pais... Eu nunca cheguei e falei que usava, nunca nem quis entrar nesse movimento porque eu achei que seria muito destrutivo talvez, muito custoso, ia me causar certa frustração então... Eu sou usuário e continuo usando, mas, eles [pais] fingem que não sabem que eu uso.

Para o Grupo 1, em cidades do interior onde as pessoas tendem a ser mais conservadoras, a questão da maconha como potencialmente geradora de preconceito e discriminação fica ainda mais evidente: "Eu tenho certeza! Tem alguns amigos meus que se for na minha casa, na minha cidade, que é uma cidade pequena, todo mundo vai falar: 'B. [mãe], D. se perdeu! Tá fumando maconha', tá não sei o quê..."

Alguns participantes do Grupo 1 relatam entender que há usuários de maconha que aceitam o estereótipo de 'maconheiro' como forma de identidade política de 
alguém emancipado e como forma de ser incluído, ainda que reconheçam a inexistência de uma visão política homogênea entre usuários de maconha. Discutem ter certo medo e insegurança com relação aos riscos relacionados ao uso da maconha. Reconhecem que o efeito da maconha pode variar de sujeito para sujeito; assim, para eles, é mito do senso comum dizer que a maconha teria efeitos calmantes. MacRae e Simões (2000), nesse sentido, defendem que a maconha é uma substância sui generis e que as experiências subjetivas são diversas e variam de situação para situação.

\section{VISÃO DOS FAMILIARES ACERCA DA MACONHA}

Ambos os grupos relatam observar grande dificuldade em conversar com os seus familiares sobre a maconha. Os familiares se apresentam relutantes em mudar suas concepções e, segundo eles, não incorporam novas informações a respeito do assunto, conforme relatos de dois jovens participantes: "Então... Na minha cidade muita gente fuma, mas ninguém conversa sobre isso"; "Penso na maconha como uma situação bem delicada, mais pelo desconhecimento".

Para os participantes do Grupo 1, seus familiares pressupõem maior risco de envolvimento com outras drogas ilícitas a partir do uso da maconha. A maioridade retiraria a responsabilidade dos familiares sobre as suas escolhas e comportamentos, sendo assim, há maior tolerância do uso entre os mais velhos do que entre jovens que convivem com suas famílias.

Quanto ao Grupo 2, para seus familiares o círculo de amizade dos filhos é uma preocupação, principalmente nos períodos em que se encontram na rua junto de amigos. Esse medo é relacionado com a possibilidade de terem conflitos com a lei. A presença de usuários de drogas na família e seu envolvimento com o tráfico foi apontado por parte dos jovens do Grupo 2 como algo que faz parte do seu cotidiano. Destacaram, ainda, que os pais podem ser modelos para o uso ou não, tanto da maconha quanto de outras drogas.

De acordo com o Grupo 2 a informação transmitida por seus familiares reforça os aspectos negativos do consumo. No entanto, em seus relatos, denunciam observar uma contradição: são alertados acerca de conflitos com a lei decorrentes da relação com drogas ilícitas por pessoas próximas, mas sentem-se alijados de opinarem sobre as razões da distinção entre drogas cujo consumo é tolerável (lícitas) e intolerável (ilícitas).

Os jovens que compuseram o Grupo 1 relatam que seus familiares veem o usuário de maconha, de uma forma geral, como criminoso, marginal, 'vagabundo'. Segundo eles, pelo desconhecimento da substância os familiares fantasiam quanto à experiência de uso e, sendo assim, os conflitos familiares são intensificados quando há revelação de que alguém da família é usuário de maconha: "eu saio para fumar maconha e... Volto assim, viajando... Aí minha mãe acha que eu... Saí para fazer um assalto sabe... Parece que você se 
envolver com maconha é automaticamente você se envolver com algo que é destrutivo, criminoso". De acordo com Rybka, Nascimento e Guzzo (2018),

A estigmatização e a criminalização de determinadas substâncias psicoativas em determinados contextos sociais de uso tem sido, há aproximadamente cem anos, uma poderosa ferramenta de desqualificação de grupos sociais específicos e de autorização para a execução das mais diversas formas de violência contra os mesmos (p.101).

Moreira et al. (2016) observaram que $86,5 \%$ das pessoas entrevistadas acreditam que a maconha é porta de entrada para outras drogas e $71 \%$ disseram acreditar que a maconha acaba com a vida das pessoas. Na visão do Grupo 1, devido à falta de informações, os familiares concebem a maconha como porta de entrada para outras drogas consideradas mais perigosas. Para os familiares dos jovens entrevistados, a maconha é vista como perigosa e 'demoníaca', em especial, quando estes são mais conservadores e religiosos. Houve apenas um relato em que o jovem, por meio de muitos diálogos, propiciou que o familiar o aceitasse como usuário, possibilitando lidar melhor com o sentimento de culpa.

De forma geral, para os jovens de ambos os grupos, há uma preocupação dos seus familiares em relação ao uso da maconha e o futuro dos filhos, análise que corrobora com o estudo de Coutinho et al. (2004). Nesse estudo, as representações sociais dos universitários, associadas à esfera familiar, foram relacionadas a elementos afetivo-emocionais, onde as figuras parentais demonstram preocupar-se sobremaneira com o futuro dos filhos.

\section{PAPEL/LUGAR DA MACONHA}

Segundo o relato dos jovens que compuseram ambos os grupos, a maconha promove a criatividade dos usuários, propicia um momento de lazer, descontração e melhora o apetite. Para eles a maconha tem funções diferentes para cada sujeito, podendo, também, ser utilizada como uma forma de enfrentar ou esquecer a realidade ('válvula de escape') ou como possibilidade de novos relacionamentos interpessoais.

Para os participantes do Grupo 2 o efeito da maconha varia de acordo com cada sujeito e a relação com a substância é tida por muitos como modismo (estilo de vida/diversão). Seu uso é relatado também como tendo a finalidade de promover o que denominam 'tranquilidade' para o usuário. Crippa, Zuardi e Hallak (2010), ao discutirem sobre os usos terapêutico dos canabinoides em Psiquiatria, destacam, dentre seus efeitos, sua ação ansiolítica.

Para o Grupo 1 a maconha pode ser utilizada com diferentes fins: para se inspirar, para ler, dormir, conversar e refletir. De acordo com esses jovens a maconha promove uma abertura para novas possibilidades. O uso proporciona o autoconhecimento sobre a relação com a substância e sobre as possíveis 
combinações com outros psicoativos, como por exemplo, o álcool. Fonseca et al. (2007), ratificando tais representações, observaram que estudantes de Psicologia do sexo masculino possuem representações da maconha como uma planta cujo uso estimula algo bom e que também promove a descontração, o prazer e a introspecção.

As experiências de uso dos jovens podem ser entendidas como um processo de familiarização de algo que é novo ao grupo. Classificando e nomeando essas experiências os jovens transformam-na em um conhecimento capaz de influenciar outras pessoas, revelando-se como uma realidade para este grupo específico (Moscovici, 2012).

\section{MOTIVAÇÃO/INFLUÊNCIA PARA O USO DA MACONHA}

A curiosidade foi relatada como o principal fator motivacional para o uso da maconha nos dois grupos. Foi destacado pelos jovens do Grupo 2 a influência de pares como fator determinante para o uso, isto é, as amizades, para eles, influenciam a decisão dos jovens de fazer ou não uso da maconha. Wagner (2007) e Gómez (2001) também apontam para a influência de pares no consumo da maconha, apontando também que o padrão de uso prejudicial pode ter a finalidade de fuga e/ou enfrentamento de problemas decorrentes das condições socioeconômicas, momentos de fragilidade ou problemas familiares como brigas/discussões. Os participantes do Grupo 2 também relataram que tentam se afastar ao máximo de pessoas que fazem uso (amigos envolvidos com tráfico) frequentemente por desejo dos seus familiares.

Para os jovens do Grupo 1 o contexto, o local e o momento em que se encontram são influências para o consumo da maconha. Para eles, os amigos que não fazem uso não se afastam dos que o fazem, e o círculo de amizades é permissivo, não sendo imposto ao jovem que ele faça o uso para que pertença ao grupo. Relatam, ainda, que uma das motivações para o uso é se sentir pertencente e aceito em um grupo, mas também se preocupam com a necessidade da diferenciação. Para eles, a universidade promove um sentimento de liberdade, de emancipação e nesse espaço há a possibilidade de contato com outras culturas e pessoas, o que acarreta mudanças nos seus valores.

Coutinho et al. (2004) destacam que para os universitários das áreas de saúde, tecnologia e jurídica as causas para o uso da maconha estão em primeiro lugar relacionadas à fuga de problemas, em segundo lugar ao prazer, em terceiro à curiosidade e em último lugar à influência de amigos. Esses quatro aspectos foram também abordados acima pelos jovens que participaram da presente pesquisa, e são corroborados também, pelos estudos de Arnaud (1996) e Pereira (2002).

\section{CONTEXTO DE USO DA MACONHA}


Na perspectiva dos jovens do Grupo 1 , diferentes contextos e situações sociais promovem diferentes significações acerca do consumo da maconha. Expressam a compreensão de que a universidade, comparada a um bairro periférico, é um contexto entendido como mais protegido para essa prática, o que possibilita aos jovens experienciar os efeitos da maconha de formas distintas. Eles reconhecem que a aquisição da maconha é algo que traz certos riscos, uma vez que é preciso comprá-la com traficantes.

Os jovens do Grupo 2 relataram o uso precoce da maconha por parte de seus pares e, consequentemente, a eventual presença do Conselho Tutelar e da Polícia Militar para vigilância e registro de ocorrências, uma vez que o caráter ilícito da droga é incutido pelos pais desde muito cedo. Ter contato inclusive visual com a comercialização e uso das substâncias em diferentes pontos do bairro é algo que faz parte do cotidiano de parte desses jovens, conforme seus relatos. A vivência dessas experiências no seu cotidiano expressa e forma as suas representações acerca da maconha e outras drogas ilícitas, constituindo o que Moscovici (2012) denomina um universo consensual, enquanto saberes produzidos no cotidiano das pessoas, no senso comum. Segundo Nascimento (2018), há uma forte relação entre o uso da maconha e o cigarro que se relacionava aos negros, africanos, escravos e indígenas caracterizando uma parcela da sociedade entendida como pobre, desprovida, desfavorecida havendo assim, ainda hoje, uma tentativa de controle desse grupo social por parte do Estado.

Para os jovens do Grupo 1 são necessárias mais discussões sobre a maconha inclusive no espaço da universidade, pois é preciso refletir sobre a questão e assim minimizar os preconceitos provenientes da falta de informação. Os jovens acreditam que há um silenciamento da universidade frente a essa temática. $\mathrm{Na}$ universidade em questão o uso é segregado, ocorrendo, segundo os participantes do grupo focal, em uma área específica e discreta: "acho que isso é falta de conhecimento. Essa falta de espaço para dialogar com as pessoas que não conhecem. A mídia coloca só de forma negativa, então a pessoa se baseia nisso, então eu acho que essas coisas, assim, tem que conversar mesmo e mostrar todos os lados da maconha".

\section{POSICIONAMENTO DA ESCOLA/UNIVERSIDADE FRENTE À MACONHA}

Jovens do Grupo 2 relataram o medo dos professores de ter contato com o aluno usuário de maconha. Relatam que muitos professores pressupõem que tais usuários são 'perigosos' por terem algum envolvimento com o tráfico e poderem manifestar reações agressivas.

A escola, segundo os jovens do Grupo 2, é compreendida como um meio para o acesso a informações em relação aos benefícios e prejuízos do uso da maconha, sendo o Programa Educacional de Resistência às Drogas (PROERD) um dos principais agentes de informação. Ainda de acordo com esses jovens o fracasso da família em transmitir valores que protejam o jovem do uso prejudicial faz com 
que a escola assuma um papel que deveria ser da família, o que leva a uma sobrecarga dessa instituição. Enfatizaram, assim, que o uso da maconha é responsabilidade do jovem e não da escola.

Segundo os jovens do Grupo 1, por sua vez, há ambiguidades na forma como os professores abordam o tema. Para eles, os professores são formadores de opinião e suas falas têm consequências na elaboração das imagens sociais da maconha. Professores com tendências proibicionistas legitimariam o estereótipo do 'maconheiro' (usa dread, frequenta determinado curso etc.), enquanto outros seguem a lógica antiproibicionista e expressam preocupação acerca de como os alunos estão se relacionando com o álcool e outras drogas.

A análise do grupo focal possibilitou perceber que para os jovens do Grupo 1 a universidade como instituição se relaciona com a maconha da mesma maneira que o senso comum, isto é, há pouca promoção de debates e discussões sobre o tema, gerando reprodução dos preconceitos. Eles relataram ainda que, durante o período de recesso escolar, o acesso ao espaço da universidade é restringido. Acreditam que seja uma forma de impedir que usuários de maconha utilizem o local discreto e reservado cotidianamente para este fim.

\section{CONSEQUÊNCIAS DECORRENTES DO USO DA MACONHA}

Segundo os jovens do Grupo 2, o vínculo do familiar com o usuário é afetado quando há envolvimento em atos como roubo ou furto. Os jovens do Grupo 1 também relataram que o uso da maconha pode causar conflitos familiares, podendo o usuário se afastar de sua família. Há apenas um relato em que houve a aproximação do familiar com o filho que é usuário, com a aceitação acontecendo após muitos diálogos. Na pesquisa de Coutinho et al. (2004) os universitários participantes da pesquisa também defendem que as consequências do uso da maconha afetam grandemente a esfera familiar, e ainda a esfera social e profissional.

Em relação às consequências decorrentes do uso da maconha, os jovens do Grupo 2 relataram que podem ser positivas ou negativas. O uso medicinal da maconha (tratamento) e, inclusive, seu uso como coadjuvante em situações de trabalho foram descritos como sendo consequências positivas. A probabilidade de a maconha causar dependência, o envolvimento em brigas, a internação, a prisão decorrente do envolvimento com drogas e o roubo para sustentar o uso são consideradas aspectos negativos. Porém, os jovens do Grupo 2 destacam que estas consequências não seriam tão evidentes como no caso do crack.

Os jovens do Grupo 1, por sua vez, veem como consequências positivas do uso da maconha o fato dela estimular a imaginação e os sentimentos, aguçar a percepção dos detalhes e a oportunidade para se tornarem mais críticos e politizados, possibilidade de autoconhecimento, de novas relações sociais. Outra vantagem é poder dialogar sobre o tema com o grupo sem ser reprimido ou censurado. Além disso, o uso, por si só, promoveria o interesse em buscar mais 
informações sobre a maconha. Laranjeira, Jungerman e Dunn (1998), apontam que a maconha proporcionaria efeitos prazerosos como sensação de relaxamento, estimulação dos sentidos, euforia e aumento da libido. Já com relação às consequências negativas, os jovens do Grupo 1 reconhecem que os efeitos da maconha podem não corresponder ao esperado uma vez que ela é potencialmente adulterada. Relataram ainda, viver conflitos uma vez que os valores morais, familiares e sociais se contrapõem à vontade de experimentar novas sensações, gerando um sentimento de culpa: "quando eu penso em maconha... Penso que é algo que de certa forma delata pelo seu caráter transgressor. Mas... Penso também em amizades, em momentos, penso em relações que construí a partir e na própria relação com a maconha".

Pode-se inferir que os jovens que participaram da pesquisa têm acesso ao que Moscovici (2012) denomina universo consensual, visto que os conhecimentos provindos desse universo são moldados, reinterpretados pelos jovens de forma a se tornarem familiares, ganhando uma nova roupagem e significações próprias. A socialização desses jovens possibilita interpretações acerca das suas vivências, tornando-as comuns a esse grupo social. Com relação ao universo reificado que diz respeito ao conhecimento científico, formal, o Grupo 2 tem acesso através da escola, mídias televisivas e internet, uma vez que alguns dos participantes desse grupo estavam cursando o ensino médio e não tinham feito um curso superior até o momento da pesquisa. Já o Grupo 1, além dos já citados anteriormente, teriam acesso aos congressos, seminários, professores que trabalhavam na área, grupo de estudos, de pesquisas e extensão oferecidos pela universidade.

\section{CONSIDERAÇÕES FINAIS}

Como produção de saberes que se constroem no cotidiano dos jovens entrevistados a Teoria das Representações Sociais auxiliou na compreensão e na análise desses conhecimentos, bem como na observação das múltiplas visões apreendidas durante a interação dos participantes no grupo focal.

Observou-se, de uma maneira geral, que as imagens associadas à maconha para os jovens do Grupo 2 se sustentam em representações sociais de conotação negativa como tráfico, violência e escalada para drogas tidas como mais perigosas. Nesse sentido, segundo Rocha (2013), "discursos ideologizados com base no proibicionismo fazem com que os adolescentes trabalhadores do tráfico de drogas ganhem status de traficantes perigosos e recebam o estigma de inimigos sociais, justificando a criminalização da juventude pobre e a efetivação do Estado penal" (p. 562). Já com relação a visão dos jovens do Grupo 1, as representações são ambivalentes quanto ao seu caráter afetivo, ora com conotações mais positivas como possibilidade de abertura para se tornarem mais politizados, mais críticos, maior percepção aos detalhes, ora com conotações mais negativas como sentimentos de culpa e produção de conflitos familiares. 
No que diz respeito às consequências decorrentes do uso, observou-se que os jovens do Grupo 1 relatam mais aspectos positivos do que os jovens do Grupo 2, possibilitando inferir que o contexto em que se faz o uso da maconha promove experiências distintas relacionadas à substância. Não obstante, os principais alvos do preconceito, da estigmatização e da criminalização seletiva são membros de grupos raciais e de classe marginalizadas, dos quais fazem parte da maioria dos participantes do Grupo 2.

Nas discussões sobre como os jovens acreditam que seus familiares veem a maconha, observou-se, inclusive, um maior volume de verbalização nos relatos dos jovens do Grupo 1 em comparação aos jovens do Grupo 2. Isso sugere que há uma menor aceitação e provavelmente maior preconceito por parte dos familiares dos jovens do Grupo 1, em sua maioria provenientes de famílias de classe média, com relação à usuários de maconha. Sugere também pouca abertura por parte dos familiares do Grupo 2 para dialogar sobre o tema com seus filhos.

Observou-se a existência de distintas representações sociais sobre o uso da maconha conforme o contexto social dos participantes da pesquisa. Para os jovens do Grupo 1 há maior permissividade com relação ao uso da maconha no contexto universitário, ainda que relatem que seus familiares suponham ser o uso da maconha porta de entrada para drogas entendidas como mais perigosas. Para os jovens do Grupo 2 o uso da maconha é ressaltado parcialmente como uma contravenção. Assim, notou-se que as representações sociais da maconha entre os dois grupos são semelhantes em alguns aspectos. O uso da maconha na visão dos jovens participantes do projeto social, embora haja o aspecto da contravenção, apresenta aspectos ambíguos: manifestam ter conhecimento sobre os problemas relacionados à Lei apesar de alguns conviverem diariamente com a comercialização de drogas ilícitas, e relatam repressão familiar com relação ao uso de maconha sendo que, em alguns casos, há familiares que fazem uso de drogas ilícitas. De maneira geral os jovens participantes do projeto social apresentam mais representações negativas no que se refere à maconha do que os jovens universitários.

Durante o processo de recrutamento dos participantes, em especial do Grupo 2, foi possível observar que o tema da maconha causava certo desconforto, e isso dificultava a aceitação para falar sobre a temática. Em diversas oportunidades, previamente e durante os grupos focais, as mediadoras enfatizaram que o objetivo da pesquisa não era entrevistar usuários de maconha e sim ouvir o que jovens tinham a dizer a respeito. Ainda assim, houve uma grande dificuldade em recrutar um número maior de participantes.

A pesquisa apresenta limites com relação ao número amostral, que não representa a maior parcela dos jovens que estudam na universidade e dos que fazem parte do projeto social. Entretanto, proporcionou identificar e comparar representações desses grupos que podem ser comuns, em certos aspectos, aos 
demais. De toda forma, pesquisas qualitativas são caracterizadas pelo aprofundamento no discurso de atores sociais acerca de determinado fenômeno, e não na sua generalização em nível estatístico, visando, assim, uma generalização de tipo naturalístico.

Não foi possível aprofundar os contextos socioculturais de cada grupo, as ações de repressão e de segurança pública que têm influência sobre as suas vivências e, também, as representações sociais relacionadas ao uso medicinal da cannabis, tendo sido valorizada, aqui, a questão do consumo da maconha de forma geral. Dada o debate e as polêmicas em torno do tema, sugere-se a realização de estudos que tratem especificamente das representações sociais de jovens sobre a cannabis medicinal, bem como estudos cujos participantes sejam oriundos de uma diversidade de territórios. Este trabalho também não aprofundou em algumas variáveis como o gênero, religião e identificação étnico-racial, que podem ter influência sobre as representações sociais acerca da cannabis.

O tema da maconha costuma ser enfatizado com relação às consequências à saúde decorrentes de seu consumo agudo ou crônico, sendo negligenciada a questão das múltiplas e diferentes utilidades da planta como um todo. As falas mais reticentes no grupo focal realizado com os jovens do Grupo 2 ratificaram a necessidade da promoção de diálogos e de informação adequada sobre o tema a ser difundida nos diversos segmentos da sociedade. Por outro lado, o relativo desprezo dos possíveis efeitos negativos da maconha mostra que é necessário também investir na questão da informação entre jovens universitários.

Salienta-se que, apesar de se estar no contexto da universidade, discutir sobre drogas em geral, mais especificamente sobre a maconha, ainda gera muita resistência, tabus e a disseminação de preconceitos. Isso acentua a necessidade de promoção de diálogos sobre o tema não apenas no contexto acadêmico, mas também na sociedade em geral.

\section{REFERÊNCIAS}

Andrade, A. G., Duarte, P. C. A. V., \& Oliveira, L. G. (Eds.). (2010). I Levantamento Nacional sobre o Uso de Álcool, Tabaco e Outras Drogas entre Universitários das 27 Capitais Brasileiras. Brasília, DF: SENAD.

Arnaud, M. A F. (1996). Adolescência e maconha: A ilusão do poder (um estudo comparativo sobre a percepção de eventos utilizando-se o constructo Locus de Controle). (Dissertação de Mestrado). Universidade Federal da Paraíba, João Pessoa.

Bastos, F. I. P. M., Vasconcellos, M. T. L., Boni, R. B. D., Reis, N. B., \& Coutinho, C. F. S. (Eds.). (2017). III Levantamento Nacional sobre o uso de drogas pela população brasileira. Rio de Janeiro, RJ: FIOCRUZ/ICICT.

Bohn, A. C., Einsfeld, E., Guaragni, M. L., Rigoni, V., Silveira, E. G., \& Ficagna, T. L. (2018). Efeitos da cannabis sativa no comportamento do usuário. Anais de Medicina, (1), 47- 48.

Borges, J. (2018). O que é encarceramento em massa? Belo Horizonte, MG Letramento: Justificando.

Carlini, E. A. (2006a). A história da maconha no Brasil. Jornal Brasileiro de Psiquiatria, 55(4), 314-317. doi:10.1590/S0047-20852006000400008.

Carlini, E. A. (Ed.). (2006b). II Levantamento Domiciliar Sobre o Uso de Drogas Psicotrópicas no Brasil: Estudo Envolvendo as 108 Maiores Cidades do País-2005. São Paulo, SP: CEBRID Centro Brasileiro de Informações sobre Drogas Psicotrópicas. Disponível em 
http://www.mds.gov.br/webarquivos/arquivo/cuidados_prevencao_drogas/obid/publicacoe s/Livros/II-Levantamento-Domiciliar-sobre-o-Uso-de-Drogas-Psicotr\%C3\%B3picas-noBrasil.pdf

Centro de Referência Técnica em Psicologia e Políticas Públicas [CREPOP] (2019). Documento de referências técnicas para a atuação de psicólogas (os) em políticas públicas de álcool e outras drogas. Brasília, DF: Conselho Federal de Psicologia. Disponível em https://site.cfp.org.br/wp-content/uploads/2019/09/AlcooleOutrasDrogas_web-FINAL.pdf

Coutinho, M. P. L., Araújo, L. F., \& Gontiès, B. (2004). Uso da maconha e suas representações sociais: Estudo comparativo entre universitários. Psicologia em Estudo, 9(3), 469-477. doi:10.1590/S1413-73722004000300015

Cordeiro, I. L. S., Silva, D. M. A., \& Dalla Vecchia, M. (2016). A escola diante do aluno que faz uso de álcool e drogas: O que dizem os professores? Pesquisas e Práticas Psicossociais, 11(2), 356368.

Crippa, J. A. S., Zuardi, A. W., \& Hallak, J. E. C. (2010). Uso terapêutico dos canabinoides em psiquiatria. Brazilian Journal of Psychiatry, 32(Suppl. 1), 556-566. doi:10.1590/S151644462010000500009

Crusoé, N. M. C. (2004). A teoria das representações sociais em Moscovici e sua importância para a pesquisa em educação. Aprender - Caderno de Filosofia e Psicologia da Educação 2(2), 105-114.

Dayrell, J, Moreira, M. I. C., \& Stengel, M. (Eds.). (2011). Juventudes contemporâneas: Um mosaico de possibilidades. Belo Horizonte, $\mathrm{BH}$ : PUC Minas.

Fonseca, A. A., Azevedo, R. L. W., Araújo, L. F., Oliveira, S. F., \& Coutinho, M. P. L. (2007). Representações sociais de universitários de psicologia acerca da maconha. Estudos de Psicologia (Campinas), 24(4), 442-443. doi:10.1590/S0103-166X2007000400004.

Gómez, J. L. G. (2001). Análise dos fatores de risco e de proteção para o consumo de drogas em adolescentes. In M. L. Marinho \& V. E. Caballo (Eds.), Psicologia clínica e da saúde (pp. 5575), Londrina, PR: Ed. UEL.

Instituto Nacional de Ciência e Tecnologia para Políticas Públicas de Álcool e Outras Drogas [INPAD]. (2014). II Levantamento Nacional de Álcool e Drogas - LENAD. São Paulo, SP: UNIFESP. https://inpad.org.br/wp-content/uploads/2014/03/Lenad-II-Relat\%C3\%B3rio.pdf

Jodelet, D. (2001). Representações sociais: Um domínio em expansão. In As representações sociais (pp.17- 44). Rio de Janeiro, RJ: UERJ.

Kind, L. (2004). Notas para o trabalho com a técnica de grupos focais. Psicologia em Revista, 10(15) 124-136.

Laranjeira, R., Jungerman, S. F., \& Dunn, J. (1998). Drogas: Maconha, cocaína e crack. São Paulo, SP: Editora Contexto.

Lessa, M. A., Cavalcanti, I. L., \& Figueiredo, N. V. (2016). Derivados canabinóides e o tratamento farmacológico da dor. Revista Dor, 17(1), 47-51. doi:10.5935/1806-0013.20160012

MacRae, E., \& Simões, J. A. (2000). Rodas de fumo: O uso da maconha entre camadas médias urbanas. Salvador, BA: EDUFBA.

Malcher-Lopes, R., \& Ribeiro, S. (2007). Maconha, Cérebro e Saúde. Rio de Janeiro, RJ: Vieira \&Lent.

Minayo, M. C. S. (Ed.). (2007). O desafio da pesquisa social. In Pesquisa social: teoria, método e criatividade (pp. 9-29). Petrópolis, RJ: Vozes.

Moreira, M. R., Carvalho, A. I., Ribeiro, J. M., \& Fernandes, F. M. (2016). Agendas democráticas para o século XXI: Percepções dos(as) brasileiros(as) sobre descriminalização e legalização da maconha. Saúde em Debate, 4O(Esp.), 163-175. doi:10.1590/0103-11042016s14

Moscovici, S. (2012). O fenômeno das representações sociais. In Representações sociais: Investigações em psicologia social (9a ed., pp. 29-109). Rio de Janeiro, RJ: Vozes.

Nascimento, H. S. P. (2018). As representações sociais e as relações de estigmatização sobre usuários de maconha. In E. F. Boesmans, N. N. L. Evangelista, \& R. C. N. de Oliveira (Eds.), Série diversidade de práticas em psicologia (pp. 9-14). Fortaleza, CE: CRP11.

Oliveira, M., \& Freitas, H. M. R., (1998). Focus Group - pesquisa qualitativa: Resgatando a teoria, instrumentalizando o seu planejamento. Revista de Administração, 33(3), 83-91.

Paulo, R. M., \& Abreu, B. S. (2015). Cannabis no gerenciamento de patologias - Revisão de literatura. Revista de Divulgação Científica Sena Aires, 4(2), 136-142.

Pereira, R. C. (2002). O consumo de drogas entre universitários da UFRPE. (Dissertação de Mestrado). Universidade Federal Rural de Pernambuco, Recife. 
Peuker, A. C., Fogaça, J., \& Bizarro, L. (2006). Expectativas e beber problemático entre universitários. Psicologia: Teoria e Pesquisa, 22(2) 193-200. doi:10.1590/S0102-37722006000200009.

Ribeiro, M., Marques, A. C. P. R., Laranjeira, R., Alves, H. N. P., Araújo, M. R., Baltieri, D. A. ... Silva, C. J. da. (2005). Abuso e dependência da maconha. Revista da Associação Médica Brasileira, 51(5), 241-255. doi:10.1590/50104-42302005000500008

Rocha, A. P. (2013). Proibicionismo e a criminalização de adolescentes pobres por tráfico de drogas. Serviço Social \& Sociedade (115), 561-580. doi:10.1590/S0101-66282013000300009.

Rybka, L. N., Nascimento, J. L., \& Guzzo, R. S. L. (2018). Os mortos e feridos na "guerra às drogas": Uma crítica ao paradigma proibicionista. Estudos de Psicologia 35(1), 99-109. doi:10.1590/1982-02752018000100010

Saad, L. (2018). "Fumo de negro": A criminalização da maconha no pós-abolição. Salvador, BA: EDUFBA.

Saito, V., Wotjak, C., \& Moreira, F. (2010). Exploração farmacológica do sistema endocanabinoide: Novas perspectivas para o tratamento de transtornos de ansiedade e depressão. Revista Brasileira de Psiquiatria, 32(suppl 1), 57-514. doi:10.1590/S1516-44462010000500004

Sousa, Y. S. O., Santos, M. F. S., \& Acioli Neto, M. L. (2019). A psicologia social e os fenômenos relacionados ao "mundo das drogas". In E. R. C. Morais, F. M. L. Cruz, M. F. S. Santos, \& R. L. S. Aléssio (Eds.), Interação social e desenvolvimento humano (Vol. 1-Interfaces entre a psicologia do desenvolvimento e a psicologia social, pp. 349-379). Recife, PE: EdUFPE.

Sousa, Y.S. O., Santos, M. F. S., \& Aléssio, R. L. S. (2018). Maconha e representações sociais em matérias de jornal. Psicologia: Teoria $e$ Pesquisa, 34 (e34420). doi:10.1590/0102.3772e34420.

Souza, E. C., Araújo, A. D. I. R., Silva, A. Z., Moura, N. S., \& Machado, A. L. G (2011, outubro). Prevalência do uso de drogas entre acadêmicos de uma Universidade do Centro-Sul piauiense. Resumos do $20^{\circ}$ Seminário de Iniciação Científica, Universidade Federal do Piauí, Aracaju/SE. Disponível em http://leg.ufpi.br/20sic/Documentos/RESUMOS/Modalidade/Vida/277281aa da22045c03945dcb2ca6f2ec.pdf.

Tavares, F. B., Silva, G. B., Tomaz, A. M., Bandeira, C. O., \& Nepomucena, D. C. S. (2008, novembro). Intervindo na relação escola e drogas. Anais do $11^{\circ}$ Encontro de Iniciação à Docência. Universidade Federal da Paraíba, João Pessoa.

United Nations Office on Drugs and Crime [UNODC]. (2017). World Drug Report 2017: Executive Summary-Conclusions and Policy Implications. Viena: United Nations Office onDrugsand Crime. Disponível em https://www.unodc.org/wdr2017/field/Booklet_1_EXSUM.pdf

Wagner, M. F. (2007). Habilidades sociais em adolescentes usuários de maconha. (Dissertação de mestrado). Pontifícia Universidade Católica do Rio Grande do Sul-PUCRS, Porto Alegre.

Westphal, M. F., Bógus, C. M., \& Faria, M.M. (1996). Grupos focais: Experiências precursoras em programas educativos em saúde no Brasil. Boletim da Oficina Sanitária Panamericana, $120(6), 472-482$.

\section{AGRADECIMENTOS}

Os autores agradecem ao PIBIC/CNPq-UFSJ pelo financiamento da pesquisa.

\section{CONFLITOS DE INTERESSES}

Não há conflitos de interesses.

\section{FINANCIAMENTO}

PIBIC/CNPq-UFSJ.

\section{SOBRE OS AUTORES}

Paola Souza Dias é Psicóloga pela Universidade Federal de São João del-Rei e atua na Associação de Pais e Amigos dos Excepcionais - APAE de São João del-Rei, Minas Gerais.

E-mail: paolasd21@yahoo.com.br 
Fernanda Gomes Palata é Psicóloga pela Universidade Federal de São João del-Rei, mestre em Psicologia Forense pela Universidade Lusófana de Humanidades e Tecnologia e atua no Centro de Saúde do Sambizanga, em Luanda, Angola.

E-mail: fernandalaura1000@hotmail.com

(2) https://orcid.org/0000-0002-9695-3898

Marcelo Dalla Vecchia é Psicólogo pela Universidade Estadual Paulista "Júlio de Mesquita Filho" (Unesp), Campus de Bauru, mestre e doutor em Saúde Coletiva pela Unesp, Campus de Botucatu, e realizou estágio pós-doutoral no Instituto de Ciências Humanas da Universidade Federal de Juiz de Fora. É professor do Departamento de Psicologia da Universidade Federal de São João del-Rei e coordenador do Núcleo de Pesquisa e Intervenção nas Políticas sobre Drogas (NUPID).

E-mail: mdvecchia@ufsj.edu.br

(1) https://orcid.org/0000-0001-7537-3598 